This is the author's final, peer-reviewed manuscript as accepted for publication. The publisher-formatted version may be available through the publisher's web site or your institution's library.

\title{
Marital therapy in mainland China: a qualitative study of young adults' knowledge, attitudes, and beliefs
}

Jared R. Anderson, C. J. Aducci, Rebekah D. Adams, Matthew D. Johnson, Wenli Liu, Fuming Zheng, G. Cole Ratcliffe

\section{How to cite this manuscript}

If you make reference to this version of the manuscript, use the following information:

Anderson, J. R., Aducci, C. J., Adams, R. D., Johnson, M. D., Liu, W., Zheng. F., \& Ratcliffe, G. C. (2012). Marital therapy in mainland China: A qualitative study of young adults' knowledge, attitudes, and beliefs. Retrieved from http://krex.ksu.edu

\section{Published Version Information}

Citation: Anderson, J. R., Aducci, C. J., Adams, R. D., Johnson, M. D., Liu, W., Zheng. F., \& Ratcliffe, G. C. (2012). Marital therapy in mainland China: A qualitative study of young adults' knowledge, attitudes, and beliefs. Journal of Family Psychotherapy, 23(3), 238-254.

Copyright: Copyright @ Taylor \& Francis Group, LLC

Digital Object Identifier (DOI): doi:10.1080/08975353.2012.705669

Publisher's Link: http://dx.doi.org/10.1080/08975353.2012.705669

This item was retrieved from the K-State Research Exchange (K-REx), the institutional repository of Kansas State University. K-REx is available at http://krex.ksu.edu 
Marital Therapy in Mainland China: A Qualitative Study of Young Adults’ Knowledge, Attitudes, and Beliefs

Jared R. Anderson, C. J. Aducci, Rebekah D. Adams, Matthew D. Johnson

Kansas State University

Wenli Liu

Beijing Normal University

Fuming Zheng

South China Normal University

G. Cole Ratcliffe, B.A.

Kansas State University

Jared R. Anderson, C. J. Aducci, Rebekah D. Adams, Matthew D. Johnson, School of Family

Studies and Human Services, Kansas State University; Wenli Liu, State Key Laboratory of

Cognitive Neuroscience and Learning, Beijing Normal University; Fuming Zheng, Department

of Early Childhood Education, South China Normal University; G. Cole Ratcliffe, School of Family Studies and Human Services, Kansas State University.

Acknowledgements: The authors would like to thank Gang Wang, J. Kale Monk, Elisabeth

Beam, Rachael Rutter, and Amy Hodgdon for their contributions to this research project.

Correspondence concerning this article should be addressed to Jared R. Anderson, School of Family Studies and Human Services, Kansas State University, 209 Campus Creek Complex, Manhattan, KS 66506. E-mail: jra@ksu.edu 


\begin{abstract}
This qualitative study explored young adults’ knowledge, attitudes, and beliefs about marital therapy in Mainland China. Participants $(N=24)$ were undergraduate and graduate students attending university in Beijing and Guangzhou. Four themes emerged from the data analysis and included 1) Beliefs Regarding Marital Therapy, 2) Role of the Therapist, 3) Barriers to Seeking Marital Therapy, and 4) Greater Accessibility to Marital Therapy. In general, our participants knew little about marital therapy, were concerned that utilizing such services could bring shame to them or to their family and that the cost of such services would be beyond most citizens' means. In addition, participants believed that marital therapists would serve as experts doling out relationship advice, while the clients would generally take a passive role. Increased government support, alternative forms of treatment that included phone and web-based services as a way to protect anonymity and therefore confidentiality, and government credentialing were seen as steps that could increase the use and accessibility of marital therapy in Mainland China.
\end{abstract}

Key words: Mainland China, marital therapy, young adults, barriers to service 
Marital Therapy in Mainland China: A Qualitative Study of Young Adults’ Knowledge, Attitudes, and Beliefs

Despite entering its fourth decade of formal practice in China (Sim \& Hu, 2009), family therapy is still a new, emergent discipline with few practitioners outside the large cities that populate the east coast. Within the past decade, China has moved to a more formalized approach to treating mental health problems (for a review see Yip, 2005), and recent attention is being given to the treatment of personal and interpersonal problems from a more holistic ecosystemic perspective (Lim, Lim, Michael, Cai, \& Schock, 2010). These two factors alone bode well for marriage and family therapy (MFT) training programs and marriage and family therapists (MFTs) in China, as MFT has its roots in an ecosystemic framework that emphasizes the greater contextual factors that contribute to interpersonal difficulties (Becvar \& Becvar, 2008).

The need for well-trained, systemic and relationally oriented therapists seems great. The results of a recent epidemiological survey estimated that $17.5 \%$ of the population, or about 173 million Chinese people suffer from some form of mental disorder. Of these, approximately 158 million or over 90\% have never received professional help (Phillips et al., 2009). Additionally, increased marital problems and climbing rates of divorce throughout Asia, including China, are evident (Tseng, Ebata, Kim, Krahl, Kua, Lu et al., 2001). For example, China has experienced a 208\% increase in divorce between 1979 and 2007, with the expectation that this increase will only continue in the foreseeable future (Wang \& Zhou, 2010). Rapid social and economic changes in Asia within recent decades, particularly in the urban areas of China, have led to changes in gender roles (Shi \& Wang, 2009) and the male-female marital relationship (Shi \& Scharff, 2008). These social changes in China have led to and are expected to lead to further breakdowns in the family system and specifically distressed marital relationships (Shi \& Wang, 
2009; Tseng et al., 2001). Literature focused on child and adolescent mental health is also growing, focusing on topics as disparate as the rise in substance use and abuse (Cochrane, Chen, Conigrave, \& Hao, 2003) and internet addiction (Cao \& Su, 2007), to the negative effects of divorce on children (Dong, Wang, \& Ollendick, 2002).

Despite these seemingly large needs for mental health treatment, there are several barriers to obtaining mental health services, including a general lack of trained mental health providers, a high percentage of uninsured citizens, and a general stigma against seeking mental health services. Trained mental health clinicians are relatively scarce in China compared to the U.S. and other western countries. China has a little over 2 therapists for every 1 million people, compared to 3,000 per 1 million in the United States (Han \& Kan, 2007). Additional barriers include the estimated 800 million Chinese citizens who lack health insurance, and the lack of coverage for mental health services for those who do have insurance. Therefore, the cost of services are prohibitive for many. Finally, the stigmatization associated with persons suffering from mental health problems and this stigma that extends to the family members of the mentally ill has been well-documented (for a review, see Lauber \& Röessler, 2007). This stigmatization has been shown to effect the help-seeking behavior of those in distress (Ng, 1997), making it more likely to seek help from family or friends than a trained therapist, who is likely a stranger.

The rapid economic and social changes that have occurred in China over the last thirty years have, in part, contributed to the rise in mental health and relational problems among the Chinese population (Shi \& Wang, 2009; Tseng et al., 2001). On the other hand, this greater economic and political freedom also has the potential to influence long-standing beliefs and values against seeking outside assistance for mental illness and marital or family problems, making formal interventions to treat psychological and relational issues more acceptable. Indeed, 
as Liang and colleagues argued (2006, as cited in Sim \& Hu, 2009) these rapid socioeconomic changes require that our understanding of Chinese families needs constant updating.

Currently, there is little empirical research on the attitudes individuals from Mainland China hold toward therapy or the perceived barriers to accessing services. Therefore, the purpose of this study was to determine the attitudes toward marital therapy of a group of young adults who were all born after the Cultural Revolution (which occurred from 1964-1976) and have lived their entire lives during this period of rapid economic and social change. It was assumed that a younger demographic as well as inquiry around relational issues (i.e., problems in marriage) rather than issues defined as "mental illness” would provide important information regarding the strength of the cultural taboo against help seeking outside the realm of family and friends and led to the following research questions:

RQ1: What do young adults in China know about marital therapy?

RQ2: What expectations do they have for the role of the therapist?

RQ3: What do they see as challenges/barriers to accessing marital therapy?

RQ4: What would make it more likely/easier to access these services?

\section{Method}

Due to the limited research on MFT in China, this study was, in essence, naturally exploratory. Therefore, a qualitative methodology was employed in an effort to best answer the research questions (Moustakas, 1994). The collaboration of researchers, in both the United States and China, throughout all phases of the current study was essential to complete this project successfully.

\section{Participants}


Participants $(N=24)$ were recruited from two large metropolitan universities, one located in Beijing and the other in Guangzhou, which are the second and third largest cities in China, respectively. The participants were undergraduate and graduate students enrolled in these two universities and 12 students were interviewed at each university. Participant ages ranged from $19-27(M=22.17 ; S D=2.75)$ with nearly equal numbers of men and women (13 women and 11 men). Of the participants, 46\% were majoring in Education/Pedagogy, 29\% in Psychology, and 25\% in Science/Geography. As a stipulation for their participation, all participants were required to be at least 18 years old and currently involved in a romantic relationship. Fifty percent had been in their current relationship for less than two years and $46 \%$ had been in their current relationship for over two years.

\section{Pilot Interviews}

Pilot interviews were held with undergraduate Chinese exchange students studying at a large Midwestern university in the U. S. This was done in order to restructure the interview guide to help ensure that interview questions were adequate for potentially answering the study's larger research questions and to help estimate the approximate length that the interviews would take. The pilot interviews informed the researchers that a more exploratory approach to the study would be necessary, as it was determined from these initial interviews that little was known about marital therapy, its purposes, and its practices. The revisions of the interview guide following the pilot interviews helped attribute to the emergent design of this study.

\section{Interview Procedures}

Through campus advertisements, undergraduate and graduate students were made aware of the research project and were directed to contact WL and FZ (authors) of their interest to participate in the study. WL and FZ were responsible for coordinating interview dates and times 
with the researchers, participants, and translators. In each university, three translators were employed to participate in interview sessions and were responsible for translating interview questions asked by the researchers and the verbatim responses given by each participant. Interviews ranged between 60 and 90 minutes in length.

The construction and use of an interview guide (Patton, 2002) was most fitting for the nature of this study. The researchers mutually participated in the construction of the interview guide that was used in each interview and each researcher adhered closely to it during interviews. Since several different interviewers were used, an interview guide was necessary to ensure that the interviewers asked the same questions across all interviews. However, the innate flexibility of an interview guide grants the researchers permission to probe for further information and introduce additional questions when necessary, which helps to capture the uniqueness of each interview (Patton, 2002). All interviewers met frequently after each round of interviews to share their experiences, ensure they were adhering to the same basic principles, and to discuss trends beginning to emerge across interviews. This helped the interviewers to stay attuned with one another and to discuss issues each felt necessary to address in ensuing interviews. For instance, “What needs to change in order to make marital therapy more accessible in China?” was one particular interview question that began to emerge as being necessary to help contribute to the overall findings of this study. Therefore, this question became salient to all subsequent interviews and thus further contributed to the emergent nature of this study’s design.

\section{Coding Scheme}

The researchers used a coding scheme developed by Auerbach \& Silverstein (2003). This method begins first by identifying pieces of relevant text in the raw text (transcripts) in order to help make the raw text more manageable for the researchers. Relevant text is defined as 
statements made during interviews that appear to potentially assist in the answering of the research questions and/or aid in a better understanding of the research participants (Auerbach \& Silverstein, 2003). The raw text from all 24 interviews was analyzed independently by at least two different members of the research team in order to help prevent analysis bias. Pieces of relevant text that were identified in at least two reviews of each transcript were then noted as being repeated ideas (Auerbach \& Silverstein, 2003). Members of the research team then worked collaboratively to organize the repeated ideas into themes. The themes represent the major findings of the current study.

\section{Credibility of Procedures}

Ensuring for the reliability and validity of research findings to quantitative and qualitative studies remains essential to the overall success of any research project. For qualitative research, Lincoln and Guba (1985) note the importance of employing indicators of rigor to ensure for this “trustworthiness.” Indicators of rigor used in this study included confirmability, credibility, and transferability. To ensure for confirmability, the researchers left an audit trail (Lincoln \& Guba, 1985) documenting their work, which consisted of audio recordings of interviews, transcripts, and field notes recorded by each interviewer. Having at least two members of the research team code each transcript to identify significant statements and four members of the research team develop themes from these significant statements gave credibility to our findings. As Charlés (2007) notes, "the data is representative of the multiple constructions there are about the phenomenon” (p. 53). Finally, given that data was collected from two different cities, representing two different provinces in China, and with participants that essentially "bookended” the age range commonly associated with young adulthood, the findings from this study may be considered transferable. 


\section{Results}

\section{Beliefs Regarding Marital Therapy}

Overall, participants seemed to have little knowledge regarding marital therapy and the education or training that marital therapists need to be credentialed and to work effectively with couples. Despite holding little knowledge about this profession, the participants clearly identified a cultural stigma associated with accessing these services. Since seeking psychological help from a professional is most often associated with being mentally ill, someone who accesses such services is automatically assumed to have a mental illness. Being labeled mentally ill continues to be quite stigmatizing and could ultimately bring shame to the family name. The participants’ little knowledge about marital therapy and their openness related to the stigma associated with it account for the two subthemes that comprise the first theme.

Lack of knowledge and awareness. Participants seemed to agree that marital therapy services were difficult to access, they did not know anyone personally who worked in this area, and were unsure where an individual would go to find professional help for their relationship. Brief samples of repeated ideas that encapsulate the participants having little knowledge of marital therapy include, “don’t know what they can do,” “no one in real life” and “I just heard this name.” One participant shared the following,

Marriage therapy does not have a good development in China and many people do not have a concept of it. They don't know what it's about, so when they have problems or trouble in their marriage they don't know where they can go for help.

Although there is an identified need for such services in China, the stigma associated with receiving these services was apparent across interviews. 
Cultural stigma. Participants were readily aware of the stigma associated with mental illness in China, and had little difficulty extending this cultural stigma to marital problems and seeking help for these types of difficulties from a stranger. The stigma associated with marital problems and seeking marital help was so pervasive throughout the interviews that it impacted not only the current theme, but another, as well discussed in the "Barriers" section. Brief repeated ideas that are representative of this stigma with marital therapy include, "they will feel embarrassed,” “you're mental,” “some disaster in your family,” “we cannot accept this kind of service,” and “prejudice from society.” As one participant shared,

If they go to that kind of physician they will feel embarrassed, because the people who are around them will know something [bad] happened in your family.

\section{Role of the Therapist}

After exploration of the text associated with the participants thoughts regarding the role of the therapist, two subthemes emerged. First, the therapist as an expert describes participant's beliefs about what the therapist should do and how the therapist should be in relation to the couple. Second, the therapist as facilitator describes how the therapist works to bring understanding to each partner and the couple.

Therapist as expert. When talking about what they would expect the therapist to be doing, brief repeated ideas emerged such as "expert gives some suggestions” and "therapist will give advice.” Participants described the therapist as needing to have a great deal of experience and thus giving advice is their "main job.” The notion that the therapist provides the couple with advice and suggestions is indicative of the therapist having knowledge to pass on to the couple. As one participant stated, 
The couple who goes to the marriage therapy usually goes to get some advice or some suggestions for their relationships. First step is the therapist talks or demonstrates his or her understanding of a good, successful relationship or marriage. The second one is to show the harm that may affect their relationship if the problem goes on. The third one is to give some solutions. This is a very passive process; the couple does not talk very much during the process.

Therapist as facilitator. Common statements around the expertise of the therapist took form in participant's description of the action-oriented approach of the therapist-as-facilitator to create activities and design interventions to improve the couple relationship. Brief repeated ideas such as “create some activities to promote the relationship,” “design some activities,” and “counselor will help them analyze” were present. These techniques and activities were suggested to improve relationship functioning and solve issues within the relationship. Deviating from this “therapist as expert” position were two participants who described the primary responsibility for change as the responsibility of the couple. The therapist has expert knowledge and is available to provide advice, but not definitive answers. These two participants were currently graduate students in psychology, therefore they likely had been exposed to therapeutic models where advice giving is not the main intervention approach.

The expert role is one that is knowledgeable and experienced. Overall participants saw the expert as having information to dispense to the couple about their relationship, with the couple often taking a passive, listening role. This knowledge was also found to be manifested in the creation of games and activities to facilitate understanding between partners.

\section{Barriers to Seeking Marital Therapy}


Three main barriers to seeking marital therapy emerged from the interviews, and this accounts for the third major finding of this study. These barriers represent challenges to the expansion of marital therapy within the country and provide more information about the current view of the field among young adults in China.

Cultural stigma. The stigma associated with accessing marital therapy services proved to be a crucial barrier in the minds of the participants that would prevent them from seeking marital therapy. If participants were having trouble in their future marriages, they expressed hesitancy around making these problems and issues “public," by seeking consultation from a stranger. One participant was forthright saying, “They [people in China] are unwilling to talk to strangers about their problems.” Other examples of brief, repeated ideas included, “do not want it (problem) to spread out and let others know about it," "would not tell their privacy to other people," and "they (community) will think bad things [are] happening in the family." Some participants identified this idea of stigma attached to seeking help outside family and close friends as a cultural expectation in China. For example, one participant shared,

Chinese conception is that difficulties or problems of the family should not be known by other people, especially strangers.

Shame. The construct around shame became apparent as repeated phrases surfaced around how participants viewed therapy. Participants shared beliefs such as "a personal failure” and “maybe you are crazy in some way.” There was fear in being laughed at and that seeking professional help for interpersonal problems brought shame to you and your family. The participants were quick to discuss how going to receive this type of service would not reflect well on the family and perhaps contribute to the manifestation of the problem, as expressed by one participant who stated, "Letting more people know their problem may make their marriage 
become worse.” There was a risk in problems being made known to someone outside the family group. One participant said it this way, "I think that it is a failure, a personal failure."

Cost constraints. The final theme that emerged regarding barriers to seeking services is the lack of information around the fees of marital therapy. This is exhibited by several brief repeated ideas, of which include, “don’t know the price,” “afraid of the high price,” “don’t know the fee.” Participants often mentioned not knowing the fee for this type of service, and also believing that it is a service only accessible to wealthy couples and not available to the general public. Not knowing how much the service would cost and whether or not people of average or lower socioeconomic status could afford or receive these services proved to be an added barrier.

\section{Greater Accessibility to Marital Therapy}

The fourth and final theme is centered on responses shared by participants that suggest ways to improve access to marital therapy services to the greater public in China. Participants shared many challenges to accessing marital therapy, but their input provides insight as to what must be essential for marital therapy to grow and to increase the overall willingness of people in China to seek such services for their marital problems. These recommendations shared by participants are represented here in four subthemes.

Ensuring for confidentiality. Mostly due to the stigma associated with receiving professional help with marital problems, of utmost importance to participants was that their work with a marital therapist remain confidential. Brief samples of repeated ideas that emphasize the importance of confidentiality include, “don’t want other people to know," "afraid of the loss of personal information,” and “don’t spread problem.” As one participant clearly stated, 
If the therapist can keep the problem of the couple as a secret and doesn't spread the problems to each other, it will make it easier because in China we don't like our problems to be known by others. We just want the problem to stay in the family.

The importance of confidentiality led participants to offer further suggestions for improving access to marriage therapy, which include offering phone and web-based services to couples.

Phone and web-based services. As a way to improve services and counter concerns about confidentiality, participants shared that marital therapists may consider offering services via phone or through internet or email. Thus, in some ways, these two subthemes are closely related. Brief repeated ideas that emerged that exemplify this subtheme include, "telephone or website,” “don’t need to have face-to-face,” and “communicate by email.” Participants suggested therapists and their clients may consider participating in a thorough phone interview about the problem, which could serve as an opportunity to become familiar with the therapist. Participants also suggested the possibility of therapists providing answers to couples’ problems via email, which also reinforces the theme around the therapist as “expert.” These recommendations were mainly seen as a way to increase the likelihood of couples accessing the services, given the client's desire to remain anonymous. As one participant shared,

Chinese prefer to communicate by email or telephone so that they do not know the real identifications of the couple.

Government credentialing and support. In order for marital therapy to become more acceptable and accessible to the Chinese public, participants seemed to agree that open support and promotion from the government of China would be important. Such support would lend credibility to the services as well as raise visibility. The government's ability to provide credentials and standards for marital therapists and to publicly document marital therapy’s ability 
to improve marital relationships would be essential for these services to not only survive, but thrive, in China. As two different participants shared,

The government administration should give more standards or certifications to guarantee the effects of this kind of service.

The government should set up more branches in schools, in working places, and in communities. More branches that would be more convenient.

In general, having the government overtly support such services may help the Chinese public build greater trust with marital therapists and in the services provided. Helping to build this trust may allow marital therapy to become more accessible in China. Having the government regulate the work of marital therapists could be directly related to having the public become more aware and accepting of these services.

Increased awareness and acceptance. In general, the public becoming more aware and accepting of marital therapy rests upon several factors. From participants, support from the Chinese government appeared to be the most critical in terms of how these services are received by the public. In order for marital therapy to become more accessible in China, it must ultimately be accepted in the Chinese culture. Of course, government support of these services would lead to greater awareness and acceptance, and therefore, these final two subthemes are closely related. Sample repeated ideas for this subtheme include, “advertising," “it can be promoted,” and “TV programs.” One possibility mentioned by participants was that the government could devote greater efforts to advertising these types of services as a way of having the public become more aware of such services. As one participant stated, More advertisement, because people here know little about marriage therapy. 
Likewise, the government establishing a means to "get the word out" to the public could also help enhance the public's perception of marital therapists and the services. For instance, one participant shared,

When the couple gets married they should go to some administration office and when they get the certificate the official should inform them that there is this kind of therapy. Finally, participants seemed to agree that if the Chinese culture became more accepting of these services, then it would ultimately increase the likelihood of couples accessing marital therapy. The government would need to play a critical role in this awareness and acceptance.

\section{Discussion}

This study utilized qualitative interviewing methodology to understand the knowledge, attitudes, and beliefs about marital therapy among a group of young adults in Mainland China. In general, our participants knew little about marital therapy, were concerned that utilizing such services could bring shame to them or to their family and that the cost of such services would be beyond most citizens' means. In addition, participants believed that marital therapists would serve as experts doling out relationship advice, while the clients would generally take a passive role. Increased government support, alternative forms of treatment that included phone and webbased services as a way to protect anonymity and therefore confidentiality, and government credentialing were seen as steps that could increase the use and accessibility of marital therapy in Mainland China.

To some degree, it is not surprising that our participants had little knowledge of marital therapy. Psychotherapy is a nascent profession in Mainland China, with the current focus on practice primarily in the treatment of serious and persistent psychological disorders (Yip, 2005). Mental health treatment in general is only beginning to emerge in the public's conscious in the 
form of psychological centers akin to community mental health centers, but again, in general these centers focus on treating diagnosable mental health disorders rather than focusing on relationship issues and concerns, especially marital problems (Yip, 2005). As stated previously, there are very few therapists in China compared to other countries such as the U.S. (2.4 therapists per million people in Mainland China compared to 3,000 therapists per million people in the U.S.) (Han \& Kan, 2007). Psychology only recently became a core collegiate science major in the year 2000, and to our knowledge there are no family therapy specific academic programs in Mainland China. Although marriage and family therapy trainings began in the 1980s, there are only small pockets of family therapists in Mainland China (Sim \& Hu, 2009) and family therapy currently does not exist as a distinct discipline apart from psychiatry and psychology. Therefore, even among well educated, middle and upper middle class young adults living in prosperous and progressive eastern cities, psychological services in general, and marital and family therapy specifically, is still a relatively unknown service.

Despite these findings, the future of couple’s therapy and the implementation of family therapy training programs in China appears to be hopeful. The emergence of a global economy and culture matched with the birth of younger generations born after the Cultural Revolution (after 1976) means the stigmas associated with mental health and relationship problems and seeking professional assistance with these problems may diminish with time in China. Such a trend has been evident in the United States over the past three decades. The implementation of a successful television program devoted to airing family therapy sessions has exposed viewers to common family problems and the methods utilized by the therapist to treat them (Krieger, 2010). In the current study, participants had little knowledge of marital therapy, but when they did, it was sometimes stated that their familiarity came from having viewed it on television. Such 
shows may help to downplay the stigma associated with mental illness and familiarize viewers with family therapists, in turn making them more likely to seek professional help when encountering marital problems.

Further, it has recently been shown that psychotherapists in China prefer to use methods and theories developed abroad rather than those developed locally (Yin, Huang, \& Fu, 2009). Therefore, students and practitioners may welcome more systemically-based family therapy methods in their education and practices. Couples and family therapy training programs may be likely to grow as a result of enthusiasm for such theories. In addition, psychoeducational approaches to treating mental illness and relationships are perceived well in China, and this has meaningful implications for educational forums that address common relationship problems and marital/relationship enrichment (Lim et al., 2010). Given the ecosystemic framework historically and currently associated with the MFT field (Becvar \& Becvar, 2008), MFT programs and MFTs in China could be at the cutting-edge of creating and instituting the curriculums used in these psychoeducational forums.

The participants in our study expect therapists to take on the expert role and primarily disseminate knowledge and insights that will improve couple relationships. This can take the form of direct advice, as well as taking responsibility for setting up tasks and exercises that will improve the couple's relationship. These results are in line with the literature that suggests that when working with Chinese families, an authoritative, direct, educational approach that honors the family’s hierarchy is preferred (Jung, 1998; Lee \& Mock, 2005; Yim, Chau, Leung, \& Tai, 1994). Given the limited knowledge about psychotherapy in general, and marital therapy in particular, our participants likely draw from their experience with medical professions and the expert stance that is common in the doctor-patient relationship. Whether or not Chinese families 
will only respond to an authoritative, directive style of therapy or respond best to such an approach remains an open question. For example, Ma (2000) interviewed client's who participated in four to twenty therapy sessions that utilized a structural family therapy framework. Despite their expectations that therapy be primarily educational and that the therapist serve as the "teacher," the clients overwhelmingly reported that therapy was beneficial and that engagement with each other, through the traditional structural technique of enactments, was beneficial in the change process. Although just one study, the implication of this study is that therapy can be effective and families can find it useful even when the process of therapy proceeds counter to their expectations. This continues to be a fruitful area of investigation as many "Western” models of therapy continue to be adapted for use in Mainland China. A better understanding of how client expectations for treatment process influence outcome is needed.

Finally, the results of this study point to at least two key ways to increase acceptability of accessing marital therapy services while decreasing the cultural stigma associated with such services, the important role of government and the need for multiple modalities of treatment. The majority of the participants talked about an increased government role in two ways. The first involved credentialing the providers of psychotherapy services so that citizens could be confident that the services provided would be legitimate and likely to lead to improved functioning. Otherwise, participants were cautious because they would not know if someone had legitimate training and expertise. In 2002, the government did establish a three-tiered licensing system that requires increasing levels of training and expertise to practice (Lim et al., 2010). This seems to be a start to the standardization of knowledge and practice within the broader mental health field in Mainland China, though it is likely that the average citizen knows little about this credentialing system. This highlights the second important role of government that participants 
in this study outlined, the need for government to educate the people through public awareness campaigns and information about the legitimacy of seeking such services to strengthen marriage and to provide the resources necessary to grow the field.

Regarding the modalities of treatment, our participants described phone and web-based counseling as potentially more acceptable modalities of treatment than the traditional in-office sessions. Although these modalities were described mainly as ways to protect confidentiality by maintaining anonymity, they also offer a way to reach more people, especially in areas where there are few, if any therapists. Web-based treatment would be limited to the growing middle and upper classes that have internet access, but since there are currently more internet users in Mainland China than the U.S., (Internet World Stats, 2010) this is clearly a growing and potentially fruitful avenue to provide care. Additionally, web-based or DVD based relationship education programs are another option, and have been shown to be effective in the few studies that include this intervention format (Braithwaite \& Fincham, 2007; 2009; Halford, Moore, Wilson, Farrugia, \& Dyer, 2004).

\section{Limitations and Conclusion}

As with any research endeavor, there are limitations based on sample and method. The participants in this sample represented a convenience sample of current university students, both undergraduate and graduate. Therefore, these students are more educated than the average Chinese citizen their age and represent relative advantage in China given that the vast majority of high school students do not attend college. The participants were also drawn from universities located in two of the three largest cities in Mainland China. Therefore, this sample is biased toward more educated and urban participants. On the other hand, this is the sample most likely to have knowledge of marital therapy and given their significant exposure to more open economies, 
lifestyles, and attitudes associated with major cities in Mainland China, compared to rural areas, this group of participants were in many ways ideal participants for understanding where therapy services for marital problems are in the public conscience. The use of translators to facilitate the interviews is also a limitation as the translated "data" is a step removed from the "raw" data. To combat the limitations of using translators, translators were native Chinese fluent in English and were directed to provide a word for word translation of the participant's responses, rather than a summary of their response. Finally, given our desire to include a relatively large sample in our study and the timeframe we had to conduct the interviews, we had to employ three interview teams. This process undoubtedly created some variability in the interview process. In order to limit the variability in conducting these interviews, the three teams participated in pilot interviews, significant discussions occurred related to the meaning and purpose of each question, and all interviewers met to debrief after each "round" of interviews to talk about the completed interviews.

In conclusion, the results from this study suggest that much work needs to be done before marital therapy goes mainstream in Mainland China. Despite the challenges, including cultural stigma against sharing family burdens with a stranger and expecting therapists to provide expert advice to passive recipients, the current ongoing social and economic developments within China make it likely that marital therapy will become more acceptable over time. To this end, many of our participants stated that with growing cultural acceptance, they would be more likely to use such services themselves. Given marriage and family therapy’s family centered and ecosystemic framework and growing concerns regarding family and couple health and well-being in China, it is likely that the future of marriage and family therapy in China is bright. 


\section{References}

Auerbach, C. F., \& Silverstein, L. B. (2003). Qualitative data: An introduction to coding and analysis. New York: New York University Press.

Becvar, D. S., \& Becvar, R. J. (2008). Family therapy: A systemic integration. (7th ed.).

Braithwaite, S. R., \& Fincham, F. D. (2007). ePREP: Computer based prevention of relationship dysfunction, depression, and anxiety. Journal of Social and Clinical Psychology, 26, 609622.

Braithwaite, S. R., \& Fincham, F. D. (2009). A randomized clinical trial of a computer based preventive intervention: Replication and extension of ePREP. Journal of Family Psychology, 23, 32-38.

Cao, F., \& Su, L. (2007). Internet addiction among Chinese adolescents: Prevalence and psychological features. Child: Care, health, and development, 33, 275-281.

Charlés, L. L. (2007). Disarming people with words: Strategies of international communication that crisis (hostage) negotiators share with systemic clinicians. Journal of Marital and Family Therapy, 33(1), 51-68.

Cochrane, J., Chen, H., Conigrave, K. M., \& Hao, W. (2003). Alcohol and Alcoholism, 38, 537542.

Dong, Q., Wang, Y., \& Ollendick, T. H. (2002). Consequences of divorce on the adjustment of children in China. Journal of Clinical Child and Adolescent Psychology, 31, 101-110.

Halford, W. K., Moore, E., Wilson, K. L., Farrugia, C., \& Dyer, C. (2004). Benefits of flexible delivery relationship education: An evaluation of the couple CARE program. Family Relations, 53, 469-476.

Han, B., \& Kan, Z. (2007). Psychology in China. The Psychologist, 20, 734-736. 
Internet World Stats. (2010). China. Internet usage stats and population report. Retrieved from www.internetworldstats.com/asia/cn.htm on August 22nd, 2010.

Jung, M. (1998). Chinese American family therapy-A new model for clinicians. San Francisco: Jossey-Bass.

Krieger, J. (2009). Manufacturing psychological understanding: How China’s first national psychotherapy TV show teaches viewers psychological narratives of Chinese family problems. Dissertation Abstracts International: Section B. Sciences and Engineering, 70, 5170.

Lauber, C., \& Rössler, W. (2007). Stigma towards people with mental illness in developing countries in Asia. International Review of Psychiatry, 19, 157-178.

Lee, E., \& Mock, M. R. (2005). Chinese families. In M. McGoldrick, J. Giordano, and N. Garcia-Preto (Eds.), Ethnicity and family therapy (pp. 302-318). New York: Guilford.

Lim, S. L., Lim, B. K. H., Michael, R., Cai, R., \& Schock, C. K. (2010). The trajectory of counseling in China: Past, present, and future trends. Journal of Counseling and Development, 88, 4-8.

Lincoln, Y. S., \& Guba, E. G. (1985). Naturalistic inquiry. Beverly Hills, CA: Sage.

Ma, J. L. C. (2000). Treatment expectations and treatment experience of Chinese families towards family therapy: Appraisal of a common belief. Journal of Family Therapy, 22, 296-307.

McGlaughlin, L. A., \& Braun, K. L. (1998). Asian and Pacific Islander cultural values: Considerations for health care decision making. Health and Social Work, 23, 116-126.

Moustakas, C. (1994). Phenomenological research methods. Thousand Oaks, CA: Sage. 
Ng, C. H. (1997). The stigma of mental illness in Asian cultures. Australian and New Zealand Journal of Psychiatry, 31, 382-390.

Patton, M. Q. (2002). Qualitative research and evaluation methods (3rd ed.). Thousand Oaks, CA: Sage.

Phillips, M. R., Zhang, J., Shi, Q., et al (2009). Prevalence, treatment, and associated disability of mental disorders in four provinces in China during 2001-2005. The Lancet, 373, 20412053.

Shi, Q., \& Scharff, S. (2008). Social change, intercultural conflict, and marital dynamics in a Chinese marriage in brief concurrent individual and couple therapy. International Journal of Applied Psychoanalytic Studies, 5, 302-321.

Shi, L., \& Wang, L. (2009). A multilevel contextual model for couples in mainland China. In M. Rastogi \& V. Thomas (Eds.), Multicultural couple therapy (pp. 297-316). Thousand Oaks, CA: Sage.

Sim, T., \& Hu, C. (2009). Family therapy in the Forbidden City: A review of Chinese journals from 1978 to 2006. Family Process, 48, 559-583.

Tseng, W-S., Ebata, K., Kim, K-I., Krahl, W., Kua, E. H., Lu, Q., Shen, Y., Tan, E-S., \& Yang, M-J. (2001). Mental health in Asia: Social improvements and challenges. International Journal of Social Psychiatry, 47, 8-23.

Wang, Q., \& Zhou, Q. (2010). China’s divorce and remarriage rates: Trends and regional disparities. Journal of Divorce and Remarriage, 51, 257-267.

Yim, V., Chau, B., Leung, D., \& Tai, L. (1994). From individual to family therapy: An expansion of conceptualization and techniques in working with families. Hong Kong Journal of Social Work, 28, 22-32. 
Yin, K., Huang, X., \& Fu, Y. (2009). The present situation of the research on psychotherapy and counseling methods in China: Through a content analysis of articles in Chinese psychological journals. Psychological Science (China), 32, 783-787.

Yip, K. S. (2005). An historical review of the mental health services in the People's Republic of China. International Journal of Social Psychiatry, 51, 106-118. 